\title{
Identification of Causal and/or Rare Genetic Variants for Complex Traits by Targeted Resequencing in Population-based Cohorts
}

\section{Yun Kyoung Kim, Chang Bum Hong and Yoon Shin Cho*}

Division of Structural and Functional Genomics, Center for Genome Science, National Institute of Health, Seoul 122-701, Korea

\begin{abstract}
Genome-wide association studies (GWASs) have greatly contributed to the identification of common variants responsible for numerous complex traits. There are, however, unavoidable limitations in detecting causal and/or rare variants for traits in this approach, which depends on an LD-based tagging SNP microarray chip. In an effort to detect potential casual and/or rare variants for complex traits, such as type 2 diabetes (T2D) and triglycerides (TGs), we conducted a targeted resequencing of loci identified by the Korea Association REsource (KARE) GWAS. The target regions for resequencing comprised whole exons, exon-intron boundaries, and regulatory regions of genes that appeared within $1 \mathrm{Mb}$ of the GWA signal boundary. From 124 individuals selected in population-based cohorts, a total of $0.7 \mathrm{Mb}$ target regions were captured by the NimbleGen sequence capture $385 \mathrm{~K}$ array. Subsequent sequencing, carried out by the Roche 454 Genome Sequencer FLX, generated about 110,000 sequence reads per individual. Mapping of sequence reads to the human reference genome was performed using the SSAHA2 program. An average of $62.2 \%$ of total reads was mapped to targets with an average 22X-fold coverage. A total of 5,983 SNPs (average 846 SNPs per individual) were called and annotated by GATK software, with $96.5 \%$ accuracy that was estimated by comparison with Affymetrix 5.0 genotyped data in identical individuals. About $51 \%$ of total SNPs were singletons that can be considered possible rare variants in the population. Among SNPs that appeared in exons, which occupies about $20 \%$ of total SNPs, 304 nonsynonymous singletons were tested with Polyphen to predict the protein damage caused by mutation. In total, we were able to detect 9 and 6 po-
\end{abstract}

*Corresponding author: E-mail yooncho33@korea $\mathrm{kr}$ Tel +82-2-380-2262, Fax +82-2-354-1063

Accepted 2 September 2010 tentially functional rare SNPs for T2D and triglycerides, respectively, evoking a further step of replication genotyping in independent populations to prove their bona fide relevance to traits.

Keywords: genome-wide association study, type 2 diabetes (T2D), triglycerides (TG), targeted resequencing, exon

\section{Introduction}

Since the completion of the Human Genome Project (Venter et al., 2001), millions of single nucleotide polymorphisms (SNPs) have been available for understanding the pattern of the human genome structure, resulting in the construction of a high-density haplotype map (International HapMap Consortium 2005). These advances in genomics, along with the development of high-throughput and high-density microarray-based genotyping platforms, have led genome-wide association (GWA) studies to seek genetic variations related to human diseases. Indeed, GWA studies have been highly effective in identifying common variants (MAF>5\%), showing strong evidence of association with complex diseases and traits $\left(p<5 \times 10^{-7}\right)$ (Cirulli et al., 2010). Most common variants identified by GWA studies, however, have shown small effects on disease risk (e.g., odds ratio of 1.2) and low levels of heritability (Aulchenko et al., 2009; Cirulli et al., 2010; Zeggini et al., 2008). These limitations in GWA studies imply that additional genetic variants (such as rare variants) remain to be detected to explain the missing heritability of complex traits. GWA studies have shown an additional limitation in identifying causal variants for complex traits as well, since this approach depends highly on LD-based tagging SNP microarray chips.

Next-generation sequencing (NGS) technologies, such as the Illumina Genome Analyzer (GA), Roche/454 FLX system, and $A B I$ SOLiD system, recently have significantly improved throughput and reduced the cost remarkably as compared to capillary-based electrophoresis systems (Shendure et al., 2004). For example, in a single experiment using the Roche/454 FLX, the sequences of approximately 100 million reads of up to 350 bases in length can be determined (Rothberg et al., 
2008). Therefore, NGS technologies are regarded as one of many revolutionary methods of large-scale personal genome sequencing. In this regard, NGS technologies are highly attractive for overcoming the limitations of GWASs by providing a way of fine-mapping to identify causal and/or rare variants. Some rare sequence variants revealed to date by whole genome sequencing or targeted sequencing using NGS technologies have been reported for their association with rare diseases, such as Mendelian disorders ( $\mathrm{Ng}$ et al., 2010), while a few are associated with complex diseases, such as type 2 diabetes (T2D) in the large-scale population.

Recently, we conducted the Korea Association REsource (KARE) project, the first Korea GWA study for complex diseases, including T2D, as well as for various quantitative traits, including anthropometric and blood biochemical traits (Cho et al., 2009). From the KARE GWA study, we were able to identify numerous significant genome-wide common loci for diverse complex traits. Most of those loci, however, showed small effects on the traits of interest-even no functional relevance to the traits. Thus, in the hope of understanding missing heritability for complex traits of interest, we extended our findings from the KARE GWA study to the detection of causal and/or rare variants by performing targeted resequencing using the Roche 454 Genome Sequencer (GS) FLX instrument in 124 individuals, selected from Korean population-based cohorts.

\section{Methods}

\section{Samples}

For targeted resequencing, samples were selected from two population-based cohorts, the Ansung and Ansan cohorts, which were initiated as a part of the Korean Genome Epidemiologic Study (KoGES) in 2001. Sample selection was stratified to three groups in order to increase the chances of identifying causal and/or rare variants for T2D and plasma triglycerides. Group 1 samples included 40 T2D patients, diagnosed by 2006 WHO guidelines. Group 2 samples included 42 nondiabetic individuals, selected from the lower quartile of fasting plasma triglycerides (TGs) (44-56 mg/dl) in the study cohorts. Group 3 samples comprised 42 individuals, selected from the upper quartile of fasting plasma TGs (321-395 mg/dl) in the study cohorts. Thus, Group 2 samples were considered as common controls for Group 1 T2D cases as well as for Group 3 samples, which had high levels of plasma TGs. About $5 \mu \mathrm{g}$ of genomic DNA per individual was used for subsequent targeted sequence capture and sequencing experiments.

\section{Targeted capture and sequencing}

Target regions for resequencing comprised the whole exon, exon-intron boundary, and regulatory region (10 $\mathrm{kb}$ upstream from the transcription start site) of genes that appeared within $1 \mathrm{Mb}$ of the GWA signal boundary for complex traits, such as T2D and TG. Adding genes for BMI, waist-hip ratio (WHR), and bone density, based on the KARE study results, a total of 45 genes, covering about $670 \mathrm{~kb}$, were selected as targets for resequencing (Table 1). To capture the targeted regions, the NimbleGen Sequence Capture 385K array method was applied (NimbleGen, Madison, WI, USA). Sequencing of capture regions was carried out by the Roche 454 GS FLX sequencer on a large PicoTiterPlate (Roche, Basel, Switzerland) according to the manufacturer's protocols. Image analysis and base calling were performed using the GS FLX pipeline software (version 2.3) with default parameters.

\section{Read mapping}

Human genome UCSC hg18 was used as the reference for the mapping of reads produced from sequencing experiments. Mapping of sequence reads to the human reference genome was performed using the SSAHA2 (version 2.5.2) program. The reference human genome was formatted by SSAHA2 using parameters -454 for indexing/hashing before mapping. The mapping of sequence reads to the formatted reference was performed using SSAHA2. The best mapping per read was determined using the parameters -454 -best 1 . Mapped reads were changed to Binary Sequence Alignment/Map (BAM) format by samtools (version 0.1.8) using the parameters view $-b t$. Mapping results were recalibrated by the GATK program using the parameters -cov QualityscoreCovariate -cov DinucCovariate.

\section{Variant calling}

The GATK module, unified genotyper, was used for variant calling via a two-step procedure. In the first step, a raw variant call was generated with the parameters --platform ROCHE454 -confidence 50 --heterozygosity 1.000000e-03 -stand_call_conf 30.0. In the second step, a filtered variant call was produced with the parameters --filterExpression "QUAL $<30.0$ /I $A B>0.75 \& \& D P>40$ // $Q D<5.0$ // HRun $>5$ // $S B>-0.10^{\prime \prime}$.

\section{Accuracy test for sequence calls}

As an accuracy test, some of the total sequence calls generated from 124 individuals were compared with 
Table 1. Basic information of target regions for sequencing

\begin{tabular}{|c|c|c|c|c|c|c|c|c|c|}
\hline Gene & $\begin{array}{l}\text { NCBI Reference } \\
\text { Sequence }\end{array}$ & Chromosome & Start & End & $\begin{array}{l}\text { Size } \\
(\mathrm{bp})\end{array}$ & $\begin{array}{l}\text { No. of } \\
\text { exon }\end{array}$ & $\begin{array}{l}\text { Size of } \\
\text { exon (bp) }\end{array}$ & $\begin{array}{c}\text { Target } \\
\text { region (bp) }\end{array}$ & Traits \\
\hline IGF2BP2 & NM_006548 & chr3 & 186844220 & 187025521 & 181,301 & 16 & 3,671 & 20,171 & T2D \\
\hline$C D K A L 1$ & NM_017774 & chr6 & 20642666 & 21339743 & 697,077 & 16 & 2,408 & 18,908 & T2D \\
\hline$C D K N 2 A$ & NM_058195 & chr9 & 21957750 & 21984490 & 26,740 & 3 & 1,151 & 17,087 & T2D \\
\hline$C D K N 2 B$ & NM_078487 & chr9 & 21992901 & 21999312 & 6,411 & 2 & 3,984 & 19,084 & $\mathrm{~T} 2 \mathrm{D}$ \\
\hline$K C N Q 1$ & NM_000218 & chr11 & 2422796 & 2826916 & 404,120 & 16 & 3,246 & 20,107 & T2D \\
\hline DKFZp686024166 & NR_026750 & chr11 & 17329892 & 17355445 & 25,553 & 5 & 6,375 & 21,775 & $\mathrm{~T} 2 \mathrm{D}$ \\
\hline KCNJ11 & NM_000525 & chr11 & 17363371 & 17366782 & 3,411 & 1 & 3,411 & 18,411 & $\mathrm{~T} 2 \mathrm{D}$ \\
\hline$A B C C 8$ & NM_000352 & chr11 & 17371007 & 17455025 & 84,018 & 39 & 4,978 & 23,777 & $\mathrm{~T} 2 \mathrm{D}$ \\
\hline$C C D C 63$ & NM_152591 & chr12 & 109769193 & 109829721 & 60,528 & 12 & 1,945 & 18,045 & T2D \\
\hline GDAP1L1 & NM_024034 & chr20 & 42309321 & 42342427 & 33,106 & 6 & 2,244 & 17,744 & $\mathrm{~T} 2 \mathrm{D}$ \\
\hline$R 3 H D M L$ & NM_178491 & chr20 & 42399039 & 42413289 & 14,250 & 5 & 1,377 & 16,777 & T2D \\
\hline$H N F 4 A$ & $\begin{array}{l}\text { NM_001030004, } \\
\text { NM_000457 }\end{array}$ & chr20 & 42417854 & 42493444 & 75,590 & 10 & 3,239 & 19,674 & $\mathrm{~T} 2 \mathrm{D}$ \\
\hline$G C K R$ & NM_001486 & chr2 & 27573209 & 27600052 & 26,843 & 19 & 2,186 & 18,979 & TG \\
\hline ZNF512 & NM_032434 & chr2 & 27659396 & 27699467 & 40,071 & 14 & 3,426 & 19,726 & TG \\
\hline$\angle P L$ & NM_000237 & chr8 & 19840861 & 19869050 & 28,189 & 10 & 3,747 & 19,647 & $\mathrm{TG}$ \\
\hline ZNF462 & NM_021224 & chr9 & 108665198 & 108813617 & 148,419 & 13 & 8,295 & 24,495 & TG \\
\hline BUD13 & NM_032725 & chr11 & 116124100 & 116148914 & 24,814 & 10 & 2,191 & 18,091 & $\mathrm{TG}$ \\
\hline ZNF259 & NM_003904 & chr11 & 116154485 & 116163949 & 9,464 & 14 & 1,778 & 18,078 & $\mathrm{TG}$ \\
\hline KIAA0999 & NM_025164 & chr11 & 116219327 & 116474203 & 254,876 & 24 & 6,069 & 23,369 & $\mathrm{TG}$ \\
\hline MAP2K1 & NM_002755 & chr15 & 64466264 & 64570936 & 104,672 & 11 & 2,586 & 18,586 & $\mathrm{BMI}$ \\
\hline FTO & NM_001080432 & chr16 & 52295375 & 52705882 & 410,507 & 9 & 4,294 & 20,094 & $\mathrm{BMI}$ \\
\hline MC4R & NM_005912 & chr18 & 56189543 & 56190981 & 1,438 & 1 & 1,438 & 16,438 & $\mathrm{BMI}$ \\
\hline CTNNBL1 & NM_030877 & chr20 & 35755847 & 35933934 & 178,087 & 16 & 1,888 & 18,388 & $\mathrm{BMI}$ \\
\hline C12orf51 & NM_001109662 & chr12 & 111082493 & 111228421 & 145,928 & 69 & 14,089 & 35,880 & WHR \\
\hline PTPN11 & NM_002834 & chr12 & 111340918 & 111432100 & 91,182 & 16 & 6,283 & 22,783 & WHR \\
\hline HSD11B1 & NM_181755 & chr1 & 207926172 & 207974918 & 48,746 & 7 & 1,415 & 17,086 & Bone density \\
\hline ADAMTS16 & NM_139056 & chr5 & 5193442 & 5373412 & 179,970 & 23 & 4,974 & 22,174 & Bone density \\
\hline CTNND2 & NM_001332 & chr5 & 11024951 & 11957110 & 932,159 & 22 & 5,436 & 22,536 & Bone density \\
\hline HIVEP2 & NM_006734 & chr6 & 143114296 & 143308031 & 193,735 & 10 & 9,724 & 25,624 & Bone density \\
\hline$T X N D C 3$ & NM_016616 & chr7 & 37854723 & 37906527 & 51,804 & 18 & 2,311 & 18,984 & Bone density \\
\hline SFRP4 & NM_003014 & chr7 & 37912059 & 37923050 & 10,991 & 6 & 2,973 & 29,165 & Bone density \\
\hline EPDR1 & NM_017549 & $\operatorname{chr} 7$ & 37926687 & 37958067 & 31,380 & 3 & 2,598 & 7,100 & Bone density \\
\hline FAM3C & NM_001040020 & chr7 & 120776140 & 120823658 & 47,518 & 10 & 2,502 & 18,442 & Bone density \\
\hline PLXNA4 & $\begin{array}{l}\text { NM_020911, } \\
\text { NM_181775 }\end{array}$ & chr7 & 131458630 & 131911863 & 453,233 & 36 & 13,061 & 33,912 & Bone density \\
\hline$V D R$ & NM_001017535 & chr12 & 46521586 & 46585081 & 63,495 & 11 & 4,775 & 20,775 & Bone density \\
\hline NT5DC3 & NM_001031701 & chr12 & 102690210 & 102759105 & 68,895 & 14 & 7,214 & 23,514 & Bone density \\
\hline TMEM132B & NM_052907 & chr12 & 124377114 & 124709542 & 332,428 & 9 & 7,578 & 23,378 & Bone density \\
\hline FLT3 & NM_004119 & chr13 & 27475410 & 27572729 & 97,319 & 24 & 3,842 & 21,115 & Bone density \\
\hline TNFSF11 & NM_033012 & chr13 & 42034871 & 42080149 & 45,278 & 7 & 2,359 & 18,412 & Bone density \\
\hline GPC5 & NM_004466 & chr13 & 90848935 & 92317486 & $1,468,551$ & 8 & 2,878 & 18,578 & Bone density \\
\hline OSCAR & NM_133169 & chr19 & 59289744 & 59295960 & 6,216 & 5 & 1,410 & 17,336 & Bone density \\
\hline Total & & & & & $7,108,313$ & 570 & 171,349 & 844,245 & \\
\hline
\end{tabular}

TG: Triglyceride, T2D: Type 2 Diabetes, WHR: Waist Hip Ratio, BMI: Body Mass Index.

SNPs that were genotyped from the same individuals with the Affymetrix Genome-Wide Human SNP array 5.0 in the KARE project. Sequence calls for comparison were extracted by Samtools (parameter, view $-b$ ) based on genotype information of the SNPs that appeared in the targeted region.

\section{Variant annotation}

Variant annotation was performed by the GATK module GenomicAnnotator using information, including Human genome UCSC hg18, NCBI dbSNP build 130, and reference genes provided by UCSC. Annotated information 


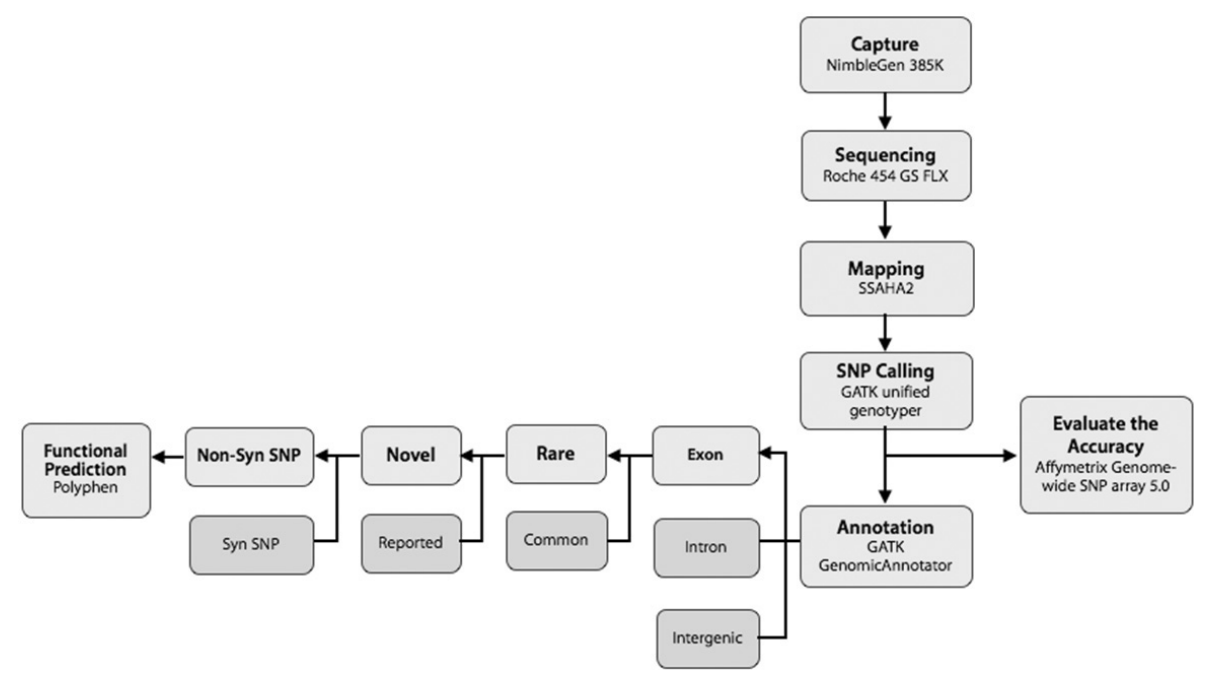

Fig. 1. Overall work flow to identify causal variants and rare variants for complex traits.
Table 2. The status of targeted sequence reads in 124 individuals

\begin{tabular}{lccccc}
\hline Group* & $\begin{array}{c}\text { Sample } \\
\text { number } \\
(\mathrm{N})\end{array}$ & $\begin{array}{c}\text { Total } \\
\text { number of } \\
\text { reads }\end{array}$ & $\begin{array}{c}\text { Total } \\
\text { number } \\
\text { of reads } \\
\text { aligned }\end{array}$ & $\begin{array}{c}\text { Number of } \\
\text { reads } \\
\text { mapped } \\
\text { in target } \\
\text { region }\end{array}$ & $\begin{array}{c}\% \text { of } \\
\text { reads } \\
\text { mapped } \\
\text { in target } \\
\text { region }\end{array}$ \\
\hline Group 1 & 40 & 110,145 & 106,334 & 66,021 & 63.2 \\
Group 2 & 42 & 108,329 & 104,657 & 60,862 & 59.1 \\
Group 3 & 42 & 106,565 & 103,194 & 65,142 & 64.4 \\
Average & & 108,317 & 104,702 & 63,976 & 62.2 \\
\hline
\end{tabular}

*Group 1, Group 2, and Group 3 correspond to T2D, shared normal controls, and individuals with high TGs, respectively.

included the dbSNP's rs IDs, SNP locations (eg, exon (3'-utr, 5'-utr) intron and intergenic regions), and SNP functions (eg, nonsynonymous SNPs and synonymous SNPs).

\section{Results and Discussion}

The GWA study has been considered a highly reliable method of identifying genetic markers associated with complex traits. However, it is usually agreed that GWA studies have limitations in understanding the total heritability for a given complex trait (Manolio et al., 2009). In an effort to explain the missing heritability of complex traits, the identification of causal variants and rare variants is a choice, along with the identification of structural variants, such as copy number variation (CNV) and epigenetic modifications.

Currently, we conducted a KARE GWA study for numerous complex traits, including T2D and fasting plas-

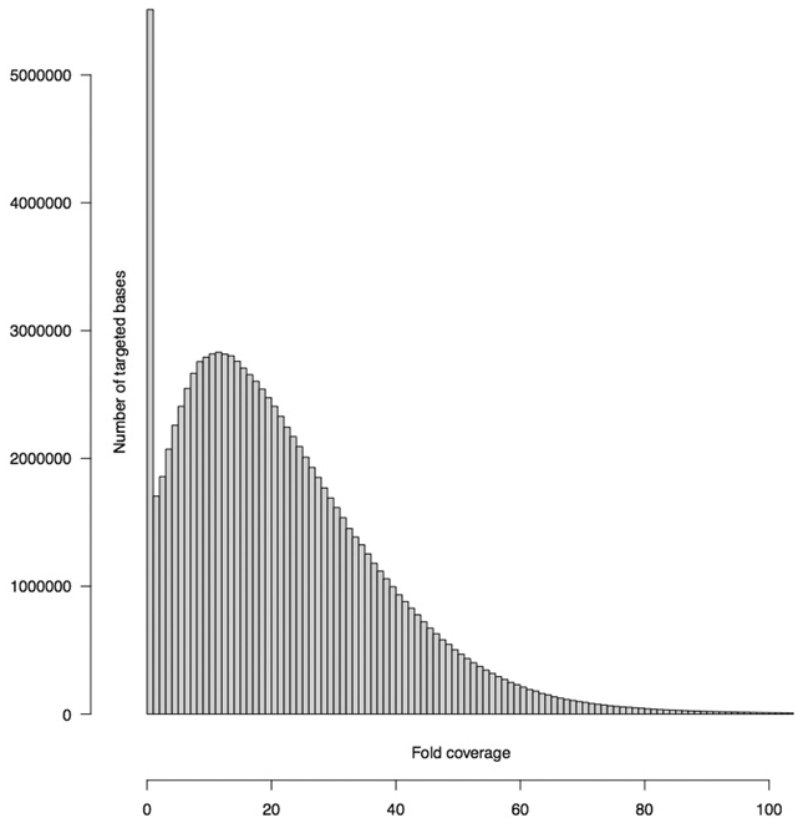

Fig. 2. The distribution of fold-coverage of mapping-targeted bases $(670 \mathrm{~kb})$ summed across the 124 individuals. The average fold-coverage for each individual was $22 \mathrm{X}$.

ma triglycerides (TGs). To detect causal variants and rare variants for T2D and TGs, we performed targeted resequencing for genes located within a $1 \mathrm{Mb}$ region of SNPs identified in the KARE GWA study for their strong evidence of association with T2D or TGs. Exons, exon-intron boundaries, and regulatory regions (10 kb upstream from the first exon) were targeted for sequencing. In addition to T2D- and TG-associated regions, we also included regions for $\mathrm{BMI}, \mathrm{WHR}$, and bone density for targeted resequencing. Samples for se- 
quencing included 40 T2D cases (Group 1), 42 nondiabetic individuals with low TGs (Group 2), and 42 individuals with high TGs (Group 3). Group 2 samples were used as controls for T2D case samples as well as high-TG samples in this study (see METHODS).

The overall study involved several steps, such as target region capture, sequencing, mapping, SNP calling, SNP annotation, and functional prediction of identified SNPs with an in silico tool (Fig. 1). Target regions for the sequence capture included 41 genes covering a total size of $670 \mathrm{~kb}$ (Table 1). Sequencing for captured regions with the Roche 454 Genome Sequencer FLX generated an average of about 108,317 reads (one read $=300-350 \mathrm{bp}$ ) per individual (Table 2). Sequence reads that passed the initial quality criteria were aligned to the reference human genome (hg18) using the SSAHA2 (version 2.5.2) program. It is estimated that
$62.2 \%$ of the reads were mapped to the target region (Table 2), with a fold coverage of $22 \mathrm{X}$ (Fig. 2). For example, the mean depth information of the targeted gene, $H S D 11 B 1$, on chromosome 1 in all 3 groups is demonstrated in Fig. 3.

Sequence variant (single nucleotide polymorphism, SNP) calling was carried out by the GATK unified genotyper module. The quality criteria for variant calling were 10X coverage by reads and base calls with a Phred-like quality score greater than 30 (Ewing and Green. 1998). The GATK Genomic Annotator module was applied to SNP annotations, based on UCSC hg18 and dbSNP build 130, generating information, such as dbSNP rs ID, SNP location, and SNP function. A total of 5,983 variants (average 846 variants per individual) were called and successfully passed our variation quality criteria. Seventeen percent of the annotated SNPs have not

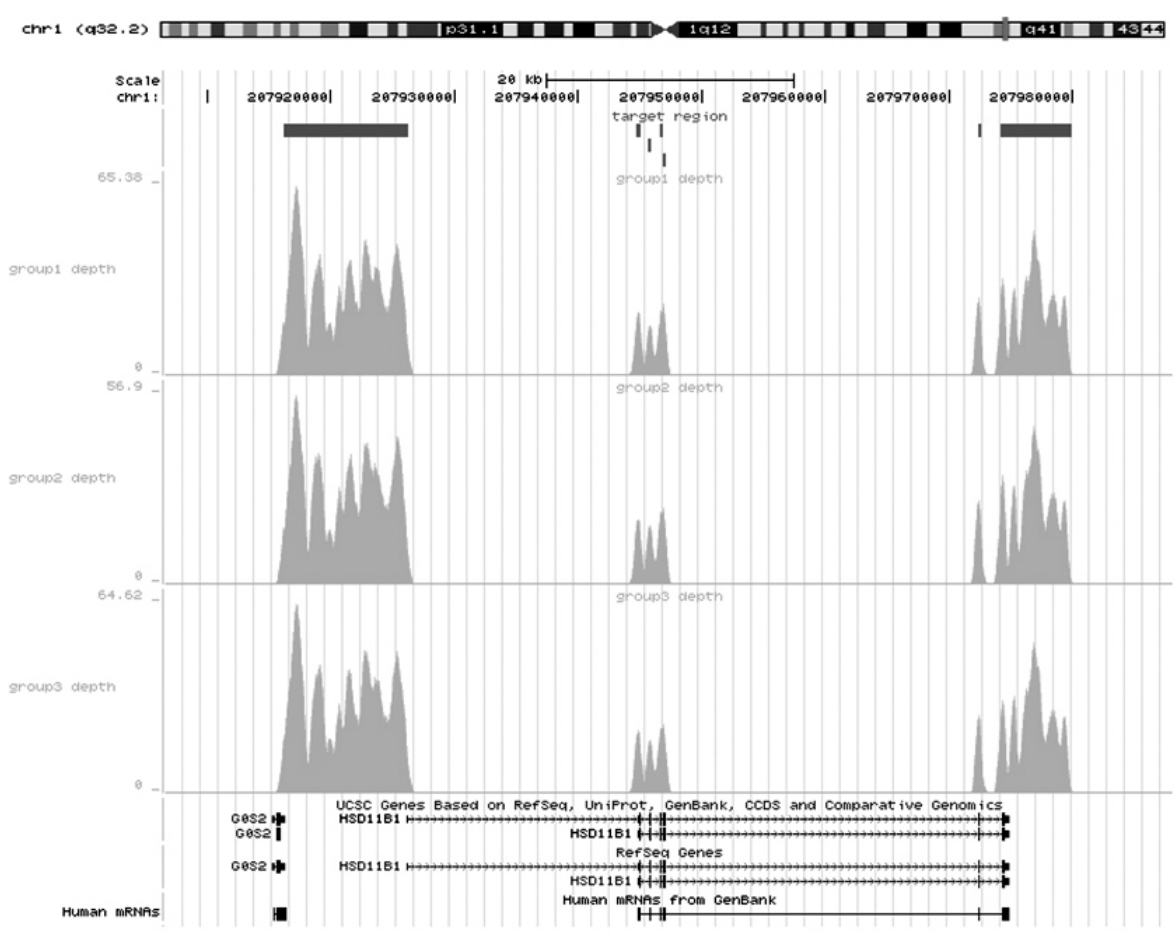

Fig. 3. Average depth of target regions for $H S D 11 B 1$.

Table 3. Summary statistics of SNP calls per individual, annotated in target regions from 124 individuals

\begin{tabular}{|c|c|c|c|c|c|c|c|c|c|c|c|c|}
\hline \multirow[b]{2}{*}{ Group } & \multirow{2}{*}{$\begin{array}{l}\text { Average } \\
\text { number of } \\
\text { SNP calls }\end{array}$} & \multirow{2}{*}{$\begin{array}{l}\text { number of } \\
\text { SNPs } \\
\text { reported in } \\
\text { dbSNP DB }\end{array}$} & \multirow{2}{*}{$\begin{array}{c}\text { Percentage } \\
\text { of novel } \\
\text { SNPs }\end{array}$} & \multicolumn{2}{|c|}{ Type } & \multicolumn{3}{|c|}{ Location } & \multicolumn{4}{|c|}{ Function of exon SNPs } \\
\hline & & & & $\begin{array}{c}\text { Number of } \\
\text { heterozygous }\end{array}$ & $\begin{array}{l}\text { Number of } \\
\text { homozygous }\end{array}$ & Exon & Intron & $\begin{array}{l}\text { Regulatory } \\
\text { region }\end{array}$ & $\begin{array}{l}\text { Non- } \\
\text { syn }\end{array}$ & syn & utr3 & utr5 \\
\hline Group 1 & 852 & 711 & $16 \%$ & 557 & 295 & 166 & 165 & 521 & 30 & 41 & 87 & 7 \\
\hline Group 2 & 851 & 702 & $17 \%$ & 536 & 315 & 172 & 162 & 517 & 31 & 43 & 91 & 7 \\
\hline Group 3 & 835 & 692 & $17 \%$ & 517 & 318 & 166 & 159 & 510 & 31 & 42 & 87 & 7 \\
\hline Average & 846 & 702 & $17 \%$ & 536 & 310 & 168 & 162 & 516 & 31 & 42 & 88 & 7 \\
\hline
\end{tabular}


been reported in the dbSNP database and are regarded as novel SNPs (Table 3). An average of 168 of the 846 SNP calls per individual appeared in exon regions, of which 31 SNPs (18.21\%) were nonsynonymous SNPs that can lead amino acid changes (Table 3).

The accuracy of sequence calls was estimated by comparing them with array-based genotype data (Affymetrix Genome-Wide Human SNP array 5.0) in the identical individual. Concordance rates were $97.95 \%$ in the homozygous reference, $95.99 \%$ in the homozygous nonreference, and $95.46 \%$ in the heterozygous genotype (Table 4).

We counted genetic variants that were shared in each individual. About $51 \%$ of the total SNP calls $(3,049$ SNPs) were singletons (Fig. 4). To detect novel SNPs that can influence T2D and TGs, we selected 304 nonsynonymous SNPs, identified from candidate genes for T2D and TGs, and tested their relevance to the function of proteins-the expression products of candidate genes-by in silico functional analysis. Analyses by PolyPhen

Table 4. Concordance of sequence calls with genotype data obtained from Affymetrix 5.0 array chip experiments

\begin{tabular}{cccc}
\hline \multirow{2}{*}{ Group } & \multicolumn{2}{c}{ Concordance with Affymetrix 5.0 array chip data } \\
\cline { 2 - 4 } & $\begin{array}{c}\text { Homozygous } \\
\text { reference }\end{array}$ & Heterozygous & $\begin{array}{c}\text { Homozygous } \\
\text { nonreference }\end{array}$ \\
\hline Group 1 & $58 / 58(97.52)$ & $31 / 32(94.55)$ & $23 / 22(95.21)$ \\
Group 2 & $56 / 57(98.04)$ & $29 / 29(96.06)$ & $23 / 23(96.11)$ \\
Group 3 & $58 / 58(98.26)$ & $30 / 30(95.73)$ & $23 / 23(96.61)$ \\
Average & $57 / 58(97.95)$ & $30 / 30(95.46)$ & $23 / 23(95.99)$ \\
\hline
\end{tabular}

(Sunyaev et al., 2001) predicted 9 novel nonsynonymous singleton SNPs for T2D and 6 for TGs that showed potentially damaging effects on candidate gene products for T2D and TGs (Table 5). Thus, it is considered that these SNPs are potentially causal and rare variants, possibly influencing T2D and fasting plasma TG levels. Validation of our findings in this study requires a repli-

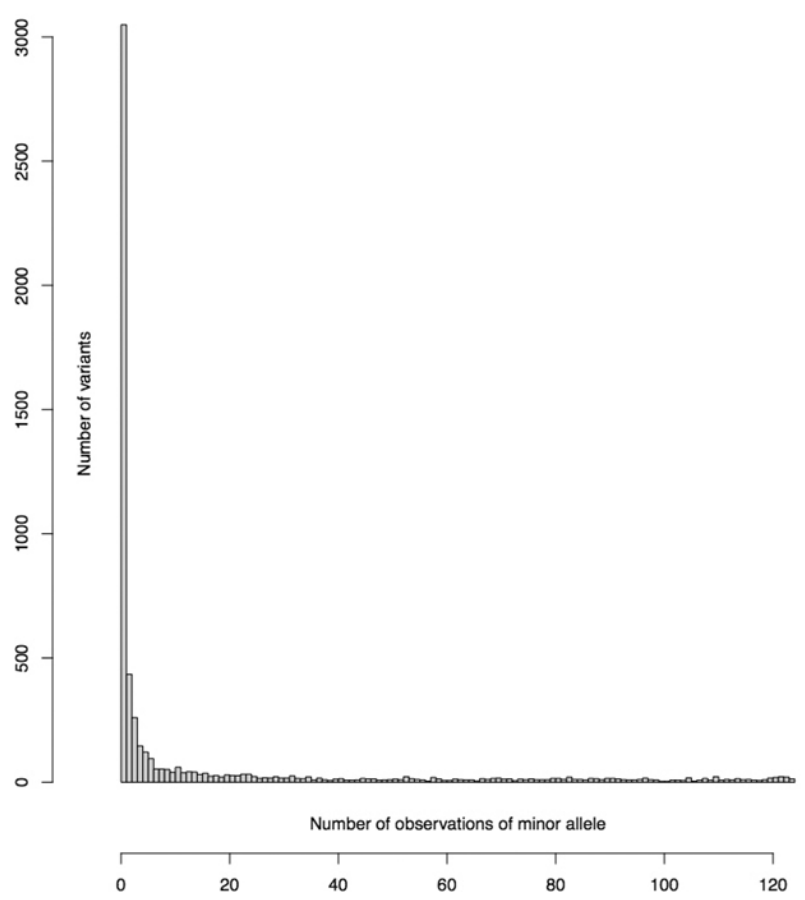

Fig. 4. Distribution of variant count.

Table 5. Results of in silico functional assay for selected novel variants

\begin{tabular}{|c|c|c|c|c|c|c|c|c|c|}
\hline Chr & Position & $\begin{array}{l}\text { Reference } \\
\text { genotype }\end{array}$ & $\begin{array}{l}\text { Observed } \\
\text { genotype }\end{array}$ & $\begin{array}{c}\text { Amino } \\
\text { acidsubstitution }\end{array}$ & AA1 & AA2 & Gene & Trait & Functional prediction* \\
\hline 3 & 186847550 & $\mathrm{~T}$ & C & Q9Y6M1 & $E$ & $\mathrm{G}$ & IGF2BP2 & T2D & Possibly damaging \\
\hline 6 & 21108512 & $G$ & $A$ & Q5VV42 & V & 1 & $C D K A L 1$ & $\mathrm{~T} 2 \mathrm{D}$ & Benign \\
\hline 9 & 21961192 & $\mathrm{~T}$ & C & P42771 & $S$ & G & $C D K N 2 A$ & $\mathrm{~T} 2 \mathrm{D}$ & Benign \\
\hline 11 & 17365424 & $\mathrm{~T}$ & $\mathrm{G}$ & B2RC52 & $\mathrm{N}$ & $\mathrm{T}$ & KCNJ11 & $\mathrm{T} 2 \mathrm{D}$ & Benign \\
\hline 11 & 17383680 & $A$ & $\mathrm{C}$ & Q09428 & $\mathrm{F}$ & $\mathrm{L}$ & $A B C C 8$ & T2D & Probably damaging \\
\hline 11 & 2505772 & $\mathrm{~T}$ & $\mathrm{C}$ & P51787 & $\mathrm{L}$ & $\mathrm{P}$ & $K C N Q 1$ & T2D & Probably damaging \\
\hline 12 & 109796040 & $\mathrm{G}$ & $A$ & Q8NA47 & M & I & $C C D C 63$ & T2D & Possibly damaging \\
\hline 20 & 42399306 & $\mathrm{C}$ & $\mathrm{T}$ & Q9H3Y0 & $A$ & V & $R 3 H D M L$ & T2D & Benign \\
\hline 20 & 42463539 & $A$ & C & P41235 & $\mathrm{N}$ & $\mathrm{T}$ & HNF4A & T2D & Benign \\
\hline 2 & 27575135 & C & $\mathrm{T}$ & Q14397 & $\mathrm{P}$ & $\mathrm{L}$ & $G C K R$ & TG & Benign \\
\hline 2 & 27684345 & $\mathrm{G}$ & $A$ & Q96ME7 & $A$ & $\mathrm{~T}$ & ZNF512 & TG & Benign \\
\hline 8 & 19862727 & $\mathrm{~T}$ & $\mathrm{C}$ & P06858 & $\mathrm{L}$ & $\mathrm{P}$ & $L P L$ & TG & Probably damaging \\
\hline 11 & 116133754 & $\mathrm{~T}$ & C & Q9BRD0 & $E$ & G & BUD13 & TG & Probably damaging \\
\hline 11 & 116155748 & $\mathrm{~T}$ & $\mathrm{C}$ & 075312 & M & V & ZNF259 & $\mathrm{TG}$ & Benign \\
\hline 11 & 116166106 & $\mathrm{~T}$ & C & Q6Q788 & $\mathrm{D}$ & $\mathrm{G}$ & APOA5 & TG & Probably damaging \\
\hline
\end{tabular}

*Prediction of functional effect of mutation, derived from the substitution effect prediction algorithm PolyPhen. T2D: Type 2 Diabetes, TG: Triglyceride. 
cation study for these SNPs in large samples of independent populations. Furthermore, a functional and clinical verification of 15 SNPs ultimately will be required to apply these findings to the treatment of T2D and hypertriglyceridemia.

\section{Acknowledgments}

This work was supported by grants from the Korea Centers for Disease Control and Prevention, Republic of Korea (4845-301, 4851-302, 4851-307).

\section{References}

Aulchenko, Y.S., Ripatti, S., Lindqvist, I., Boomsma, D., Heid, I.M., Pramstaller, P.P., Penninx, B.W., Janssens, A.C., Wilson, J.F., Spector, T., Martin, N.G., Pedersen, N.L., Kyvik, K.O., Kaprio, J., Hofman, A., Freimer, N.B., Jarvelin, M.R., Gyllensten, U., Campbell, H., Rudan, I., Johansson, A., Marroni, F., Hayward, C., Vitart, V., Jonasson, I., Pattaro, C., Wright, A., Hastie, N., Pichler, I., Hicks, A.A., Falchi, M., Willemsen, G., Hottenga, J.J., de Geus, E.J., Montgomery, G.W., Whitfield, J., Magnusson, P., Saharinen, J., Perola, M., Silander, K., Isaacs, A., Sijbrands, E.J., Uitterlinden, A.G., Witteman, J.C., Oostra, B.A., Elliott, P., Ruokonen, A., Sabatti, C., Gieger, C., Meitinger, T., Kronenberg, F., Döring, A., Wichmann, H.E., Smit, J.H., McCarthy, M.I., van Duijn, C.M., Peltonen, L., and ENGAGE Consortium. (2009). Loci influencing lipid levels and coronary heart disease risk in 16 European population cohorts. Nat. Genet. 41, 47-55.

Cho, Y.S., Go, M.J., Kim, Y.J., Heo, J.Y., Oh, J.H., Ban, H.J., Yoon, D., Lee, M.H., Kim, D.J., Park, M., Cha, S.H., Kim, J.W., Han, B.G., Min, H., Ahn, Y., Park, M.S., Han, H.R., Jang, H.Y., Cho, E.Y., Lee, J.E., Cho, N.H., Shin, C., Park, T., Park, J.W., Lee, J.K., Cardon, L., Clarke, G., McCarthy, M.I., Lee, J.Y., Lee, J.K., Oh, B., and Kim, H.L. (2009). A large-scale genome-wide association study of Asian populations uncovers genetic factors influencing eight quantitative traits. Nat. Genet. 41, 527-534.

Choi, M., Scholl, U.I., Ji, W., Liu, T., Tikhonova, I.R., Zumbo, P., Nayir, A., Bakkaloğlu, A., Ozen, S., Sanjad, S., Nelson-Williams, C., Farhi, A., Mane, S., and Lifton, R.P. (2009). Genetic diagnosis by whole exome capture and massively parallel DNA sequencing. Proc. Natl. Acad. Sci. USA 106, 19096-19101.

Cirulli, E.T., and Goldstein, D.B. (2010). Uncovering the roles of rare variants in common disease through wholegenome sequencing. Nat. Rev. Genet. 11, 415-425.

Ewing, B., and Green, P. (1998). Base-calling of automated sequencer traces using phred. II. Error probabilities. Genome Res. 8, 186-194.

Manolio, T.A., Collins, F.S., Cox, N.J., Goldstein, D.B., Hindorff, L.A., Hunter, D.J., McCarthy, M.I., Ramos, E.M., Cardon, L.R., Chakravarti, A., Cho, J.H., Guttmacher, A.E., Kong, A., Kruglyak, L., Mardis, E., Rotimi, C.N.,
Slatkin, M., Valle, D., Whittemore, A.S., Boehnke, M., Clark, A.G., Eichler, E.E., Gibson, G., Haines, J.L., Mackay, T.F., McCarroll, S.A., and Visscher, P.M. (2009) Finding the missing heritability of complex diseases. Nature 461, 747-753.

Ng, S.B., Buckingham, K.J., Lee, C., Bigham, A.W., Tabor, H.K., Dent, K.M., Huff, C.D., Shannon, P.T., Jabs, E.W., Nickerson, D.A., Shendure, J., and Bamshad, M.J. (2010). Exome sequencing identifies the cause of a mendelian disorder. Nat. Genet. 42, 30-35.

Ng, S.B., Turner, E.H., Robertson, P.D., Flygare, S.D., Bigham, A.W., Lee, C., Shaffer, T., Wong, M., Bhattacharjee, A., Eichler, E.E., Bamshad, M., Nickerson, D.A., and Shendure, J. (2009). Targeted capture and massively parallel sequencing of 12 human exomes. Nature 461, 272-276.

Rothberg, J.M., and Leamon, J.H. (2008). The development and impact of 454 sequencing. Nat. Biotechnol. 26, 1117-1124.

Shendure, J., Mitra, R.D., Varma, C., and Church, G.M. (2004). Advanced sequencing technologies: Methods and goals. Nat. Rev. Genet. 5, 335-344.

Sunyaev, S., Ramensky, V., Koch, I., Lathe, W. 3rd, Kondrashov, A.S., and Bork, P. (2001). Prediction of deleterious human alleles. Hum. Mol. Genet. 10, 591-597.

The International HapMap Consortium. (2005). A haplotype map of the human genome. Nature 437, 1299-1320.

Venter, J.C., Adams, M.D., Myers, E.W., Li, P.W., Mural, R.J., Sutton, G.G., Smith, H.O., Yandell, M., Evans, C.A., Holt, R.A., et al. (2001). The sequence of the human genome. Science 291, 1304-1351.

Zeggini, E., Scott, L.J., Saxena, R., Voight, B.F., Marchini, J.L., Hu, T., de Bakker, P.I., Abecasis, G.R., Almgren, P., Andersen, G., Ardlie, K., Boström, K.B., Bergman, R.N., Bonnycastle, L.L., Borch-Johnsen, K., Burtt, N.P., Chen, H., Chines, P.S., Daly, M.J., Deodhar, P., Ding, C.J., Doney, A.S., Duren, W.L., Elliott, K.S., Erdos, M.R., Frayling, T.M., Freathy, R.M., Gianniny, L., Grallert, H., Grarup, N., Groves, C.J., Guiducci, C., Hansen, T., Herder, C., Hitman, G.A., Hughes, T.E., Isomaa, B., Jackson, A.U., Jørgensen, T., Kong, A., Kubalanza, K., Kuruvilla, F.G., Kuusisto, J., Langenberg, C., Lango, H.,

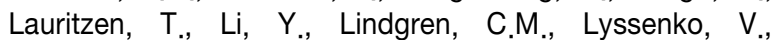
Marvelle, A.F., Meisinger, C., Midthjell, K., Mohlke, K.L., Morken, M.A., Morris, A.D., Narisu, N., Nilsson, P., Owen, K.R., Palmer, C.N., Payne, F., Perry, J.R., Pettersen, E., Platou, C., Prokopenko, I., Qi, L., Qin, L., Rayner, N.W., Rees, M., Roix, J.J., Sandbaek, A., Shields, B., Sjögren, M., Steinthorsdottir, V., Stringham, H.M., Swift, A.J., Thorleifsson, G., Thorsteinsdottir, U., Timpson, N.J., Tuomi, T., Tuomilehto, J., Walker, M., Watanabe, R.M., Weedon, M.N., Willer, C.J.; Wellcome Trust Case Control Consortium, Illig, T., Hveem, K., Hu, F.B., Laakso, M., Stefansson, K., Pedersen, O., Wareham, N.J., Barroso, I., Hattersley, A.T., Collins, F.S., Groop, L., McCarthy, M.I., Boehnke, M., and Altshuler, D. (2008). Meta-analysis of genome-wide association data and large-scale replication identifies additional susceptibility loci for type 2 diabetes. Nat. Genet. 40, 638-645. 